
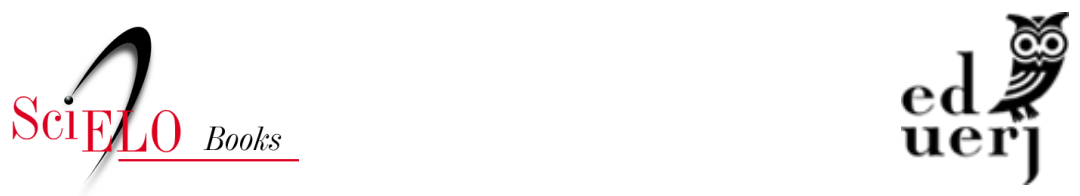

\title{
8. Joãozinho no Além: notas sobre uma narrativa fantástica
}

\author{
Vanessa Massoni da Rocha
}

\section{SciELO Books / SciELO Livros / SciELO Libros}

ROCHA, V. M. Joãozinho no Além: notas sobre uma narrativa fantástica. In: Tradução em (ent)revista: Simone Schwarz-Bart e as tradutoras brasileiras [online]. Rio de Janeiro: EDUERJ, 2021, pp. 73-78. Letras UERJ collection. ISBN: 978-65-991111-5-0. https://doi.org/10.7476/9786599111150.0008.

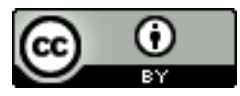

All the contents of this work, except where otherwise noted, is licensed under a Creative Commons Attribution 4.0 International license.

Todo o conteúdo deste trabalho, exceto quando houver ressalva, é publicado sob a licença Creative Commons Atribição 4.0.

Todo el contenido de esta obra, excepto donde se indique lo contrario, está bajo licencia de la licencia Creative Commons Reconocimento 4.0. 


\section{Joãozinho no Além: notas sobre uma narrativa fantástica}

A cena inicial do romance Joãozinho no Além, de 1979, reitera um procedimento estilístico das narrativas de Schwarz-Bart: parágrafos iniciais de enorme fôlego, pungentes, que conseguem, ao mesmo tempo, apresentar e resumir as intrigas que serão desenvolvidas ao longo do livro. No que tange às temáticas contempladas, renova-se, nessa obra, a relação com o espaço, os sentimentos de insularidade e de invisibilidade e a relação com a Guadalupe. Descrever o arquipélago e buscar suas relações com o continente africano se tornam caminhos para a tomada de consciência do mosaico identitário caribenho e da alteridade que permeiam o continente americano. Como salienta Simone Schwarz-Bart (apud Spear, 2013) acerca da origem do romance, "Ti Jean nasceu de um conto crioulo, que começou a magnetizar algumas experiências: minha relação com Guadalupe, África, Europa”. 
Eis a abertura do livro primeiro, aquele "onde se vê a história do mundo até o nascimento de Joãozinho Horizonte, seguida aos primeiros passos do herói na vida” (Schwarz-Bart, 1988, p. 7):

A ilha em que se passa esta história não é muito conhecida. Ela flutua no golfo do México à deriva, de certa forma, e só alguns mapas-múndi muito precisos a registram. Se você pegar um globo terrestre, será inútil olhar, sonhar, examinar, cansar a pupila de seus olhos, pois dificilmente a encontrará sem a ajuda de uma lupa. Ela surgiu recentemente no mar, há apenas um ou dois milhões de anos. E corre o boato de que ela pode desaparecer como apareceu, afundar sem pedir socorro, de repente, arrastando consigo suas montanhas e seu pequeno vulcão de enxofre, suas verdes colinas nas quais se dependuram cabanas remendadas, como suspensas no ar e seus milhões de rios tão extraordinários e ensolarados que os primeiros habitantes a batizaram assim: a ilha-das-belas-águas (Schwarz-Bart, 1988, p. 9).

Segundo romance escrito individualmente por Simone Schwarz-Bart, Joãozinho no Além se consagra inegavelmente como aquele que mais flerta com a estética do real maravilhoso e do sobrenatural. A narrativa apresenta diversos contos africanos e antilhanos que contribuem para a cartografia das peripécias do herói. Eurídice Figueiredo reconhece que Simone foi uma autora "que utilizou uma das figuras mais populares do folclore crioulo como protagonista de um romance" (1998, p. 133). A pesquisadora aproxima o personagem Joãozinho do brasileiro Pedro Malasartes, "um malandro que cria estratagemas audazes como forma de sobrevivência em condições adversas, numa sociedade extremamente estratificada, em que os pobres não têm vez nem voz" (1998, p. 134). No romance, composto por nove capítulos de dimensões incongruentes, numerados de Livro Primeiro até o Livro Nono, Joãozinho se deixa tragar por uma Besta gigante que, por haver engolido o sol, tinha condenado os guadalupenses à penúria. 
Na barriga do gigante, o menino vagueia entre o mundo dos vivos e o dos mortos, revisita o que acredita ser a África dos ancestrais e passa por muitas provas para, enfim, conseguir retornar à terra natal. A palavra Guadalupe aparece dezenas e dezenas de vezes no romance, consagrando-se como espaço afetivo para onde se faz imperativo regressar. Graças às agruras do pequeno herói, Schwarz-Bart se dedica a "inscrever o antilhano no seu espaço sociocultural" (Said, 2007, p. 14), reiterando que "o tráfico e a história da escravidão operaram um corte que torna a origem africana ilusória, errônea e alienante" (Said, 2007, p. 14). Compondo uma "epopeia que incansavelmente busca reconstituir a origem" (Malu-Meert, 1985, p. 15), a autora denuncia a escravização dos negros ainda na África e faz seu herói confrontar o discurso mítico sobre a África, discurso bradado reiteradamente pelo avô, às peripécias vivenciadas nesse continente pelo guadalupense viajante.

Suzanne Crosta, em sua análise do romance (1999), identifica que

os motivos do caçador, da Besta e das batalhas a serem travadas reforçam o principal problema da busca pela identidade. Para se conhecer, Ti Jean não deve apenas olhar no espelho, mas também ver o olhar que os outros lançam para ele. A luta contra a escravidão, contra o fatalismo, contra o racismo encontra suas expressões no motivo da Besta, nas histórias e alusões aos Devoradores, no jogo do olhar. Esses elos entre o universo sonhado e o universo real nos lembram os fundamentos da produção textual de imagens de si mesmo e do outro.

As aventuras de Joãozinho entre os continentes africano, europeu e americano se inspiram na realidade da escritora, que estudou nos três continentes, mais precisamente nas cidades de Dakar, Paris e Pointe-à-Pitre, e que transformou as riquezas e aventuras de seu percurso pessoal em inspiração para o percurso fantástico de seu herói. Transitar nos mais diversos espaços se torna a promessa romanesca de compre- 
ender sua própria dimensão, nomear suas limitações e descortinar seus aprendizados ao longo de suas andanças.

Em um diálogo com seu avô, o feiticeiro Wademba, ainda na infância, Joãozinho aprende sobre os heróis anônimos que povoam o espaço insular:

Foi assim, foi assim que se foi o amigo Obê, há muito, muito tempo... Há mais de uma vida de homem, mais de duas e de três, pois dez gerações se passaram desde que fui trazido, criança, para esta ilha à deriva. Vi muitos sóis nascerem, e há muitos outros negros dos quais gostaria de lhe falar: Ako, Mindumu, N’Décondé, Djuka o Grande, com o qual cheguei no navio, e outros, muitos outros... Mas se você voltar nessas paragens, debruce-se na grama e respire seu odor, pois são os cabelos dos heróis que dormem sob a terra... (Schwarz-Bart, 1988, p. 63).

Promovendo uma revisão da história oficial tal como descrita nas crônicas dos colonizadores, Schwarz-Bart leva a termo a premissa de que o romancista deve "suprir as falhas existentes nas histórias das colonizações” (Damato, 1995, p. 190). Com uma escrita engajada, fortemente ancorada nos costumes caribenhos, Simone entrelaça épocas, costumes, músicas, histórias, para compor romances plurais que refletem as riquezas, as tradições e as vicissitudes da antilhanidade. Neles, os heróis esquecidos passam a ser deliberadamente nomeados para poderem, enfim, ocupar o lugar que lhes cabe no panteão caribenho. Tudo se passa como se a autora tomasse as rédeas de sua história, valorizando o protagonismo dos oprimidos que foram ceifados da historiografia canônica. Trata-se de uma subjetivação capaz de restituir a dignidade por séculos usurpada e obliterada.

A conversa do herói com a rainha do Reino dos Mortos, no sexto livro da narrativa, coloca em cena dado complexo de inferioridade dos guadalupenses que a dimensão romanesca busca sobrepor: 
—Quem é você e qual é o seu nome, ó saltador de planícies?

- Meu nome é Joãozinho e sou simplesmente um homem sob as nuvens, um homem qualquer.

- Seu país?

- Chamavam-no Guadalupe - disse o exilado.

- Infelizmente...

- Rainha, rainha, não se desculpe - disse Joãozinho num riso breve -, meu país é tão pequeno que ninguém o conhece, e minha nação tão fraca que ela mal acreditava em sua própria existência... (Schwarz-Bart, 1988, p. 226)

Em outra passagem, a Guadalupe também se faz presente:

[...] Eternidades passaram-se na vã procura de um caminho, de uma trilha, de um sinal qualquer de via subterrânea que levasse à Guadalupe. Nenhum morto jamais ouvira falar desse grão, dessa poeira de país, e, se conheciam a existência de um oceano, em algum lugar, nenhum foi capaz de designar-lhe a direção precisa com o dedo (Schwarz-Bart, 1988, p. 213).

A busca pela Guadalupe natal se confunde com a descoberta das dimensões de sua identidade. $\mathrm{O}$ ato de procurar a Guadalupe configura um dispositivo romanesco de busca de si mesmo, de autocompreensão nas divagações da errância. Deslocado, desprovido de muitas maneiras de defender-se, desiludido com o retorno ao espaço ancestral, o pequeno herói compreende a imensidão do seu grão de terra e passa a reivindicar a grandeza dessa terra desconhecida que quase não figura nos mapas. A experiência do exílio torna possível o reconhecimento do lar perdido, permite a exaltação da beleza de sua pequenez, da beleza de seu sol único, de suas planícies povoadas por gente comum. Como salienta Gabrielle Said (2007, p. 110), “o real, a história e o imaginário antilhanos constituem uma fonte particularmente rica que é possível e necessária de explorar, como ilustra a produção antilhana desde os anos 
sessenta”. Por certo, "esta dimensão mágica da narrativa está intimamente ligada à sua função simbólica. $\mathrm{O}$ espaço que se abre no interior da Besta permite ao herói revisitar a cartografia guadalupense sobre o modo alegórico e se situar no mundo" (Said, 2007, p. 110). Partir, aqui, é criar laços com a ilha, reivindicá-la, exaltá-la, confundi-la com si mesmo. A experiência de partir remete, como alude Saramago (2008, p. 40-41) na premissa "é necessário sair da ilha para ver a ilha, que não nos vemos se não nos saímos de nós", ao imperativo de sairmos de nós para melhor nos olharmos. Eis a epopeia tal como foi vivenciada pelo pequeno protagonista: de sua pequenez, que metonimiza geograficamente a ilha natal, impulsiona-se a força motora para inventariar a si mesmo e a ilha de origem.

Inscrita nessa perspectiva, o legado literário de Simone Schwarz-Bart "ultrapassa o exotismo [...] e consegue, com uma sensibilidade poética e uma simplicidade rara, traduzir a esperança do povo guadalupense em busca de uma identidade profunda" (Malu-Meert, 1985, p. 9), uma vez que "a ilha é no mar/ no vento/ no barco/ no pássaro/ no arquipélago/ na terra/ mas também, nela/ a ilha é ela mesma" (Camelo, 2015, p. 54). A ilha é ela mesma, eis a conclusão a que chega o herói viajante quando constata que suas viagens e peregrinações fantásticas o aproximam da grandeza existente na exiguidade física do arquipélago antilhano. Joãozinho precisou viajar numa espécie de máquina do tempo encantada para descortinar sua identidade e compreender a realidade crioula em todas as suas dimensões. A versão estado-unidense do romance, intitulada Entre dois mundos, evidencia as heranças africanas e antilhanas como duas pontas em eterno diálogo na formação identitária do personagem. Por certo, em sua jornada, saiu de si, como defende Saramago, para se olhar com novos olhares e poder compreender melhor sua identidade e a de sua terra natal.

Epopeia antilhana, o romance foi publicado em 1979, mas seu processo de escrita, de mais de dez anos, iniciou-se antes da publicação de A ilha da chuva e do vento, em 1972. A tradução para o português, feita por Eurídice Figueiredo, foi publicada em 1988. 